\title{
ACCUMULATOR RING DESIGN FOR THE NSNS PROJECT *
}

\author{
W.T. Weng, J. Alessi, J. Beebe-Wang, M. Blaskiewicz, L. Blumberg, M. Brennan, C. Gardner, \\ Y.Y. Lee, A.U. Luccio, H. Ludewig, D. Maletic, D. Raparia, A. Ruggiero, S.Y. Zhang \\ AGS Department, Brookhaven National Laboratory, Upton, NY 11973.
}

\section{Abstract}

The goal of the proposed National Spallation Neutron Source (NSNS) is to provide a short pulse proton beam of about $0.5 \mu$ s with average beam power of $1 \mathrm{MW}$. To achieve such purpose, a proton storage ring operated at $60 \mathrm{~Hz}$ with $1 \times 10^{14}$ protons per pulse at $1 \mathrm{GeV}$ is required. The Accumulator Ring (AR) receives $1 \mathrm{msec}$ long $H^{-}$beam bunches of $28 \mathrm{~mA}$ from a $1 \mathrm{GeV}$ linac. Scope and design performance goals of the AR are presented, other possible technological choices and design options considered, but not adopted, are also briefly reviewed.

\section{INTRODUCTION}

The Oak Ridge National Laboratory is leading a conceptual design for a next generation pulsed spallation neutron source, the National Spallation Neutron Source (NSNS) [1]. There are three major accelerator systems included in Brookhaven's area of responsibility. First is the High Energy Beam Transport (HEBT) system [2]. Secondly, the Accumulator Ring (AR) system and thirdly, the Ring to Target Beam Transport (RTBT) system [3]. This paper describes the design of the $A R$ itself whose magnet and tunnel layout is shown in Fig. 1.

The proton Accumulator Ring is one of the major systems in the design of the NSNS. The primary function of the $\mathrm{AR}$ is to take the $1 \mathrm{GeV} H^{-}$beam of about $1 \mathrm{msec}$ length from the linac and convert it into a $0.5 \mu \mathrm{s}$ beam through a stripping foil in about one thousand turns. The final beam should have $1.0 \times 10^{14}$ protons per pulse, resulting in $1 \mathrm{MW}$ design average beam power at $60 \mathrm{~Hz}$ repetition rate. Provisions have been reserved for a future upgrade to $2 \mathrm{MW}$ beam power by doubling the stored current to $2.0 \times 10^{14}$ proton per pulse without changes in both the magnet and vacuum system.

One of the major performance requirements is to keep the average uncontrolled particle loss during the accumulation time to less than $2.0 \times 10^{-4}$ per pulse. The reason of this stringent requirement is to keep the residual radiation to such a level that the hands-on maintenance is possible except for a few localized areas, such as: injection, extraction and collimation. To achieve this goal, special care have been exercised in the $H^{-}$stripping, the RF stacking, and the collimator design.

This paper describes the final product of the intensive $R \& D$ efforts in the past two years. During that pe-

\footnotetext{
- Research on the NSNS is sponsored by the Division of Material Sciences, U.S. Deparment of Energy, under contract number DE-ACOS960R22464 with Lockheed Martin Energy Research Corporation for Oak Ridge National Laboratory.
}

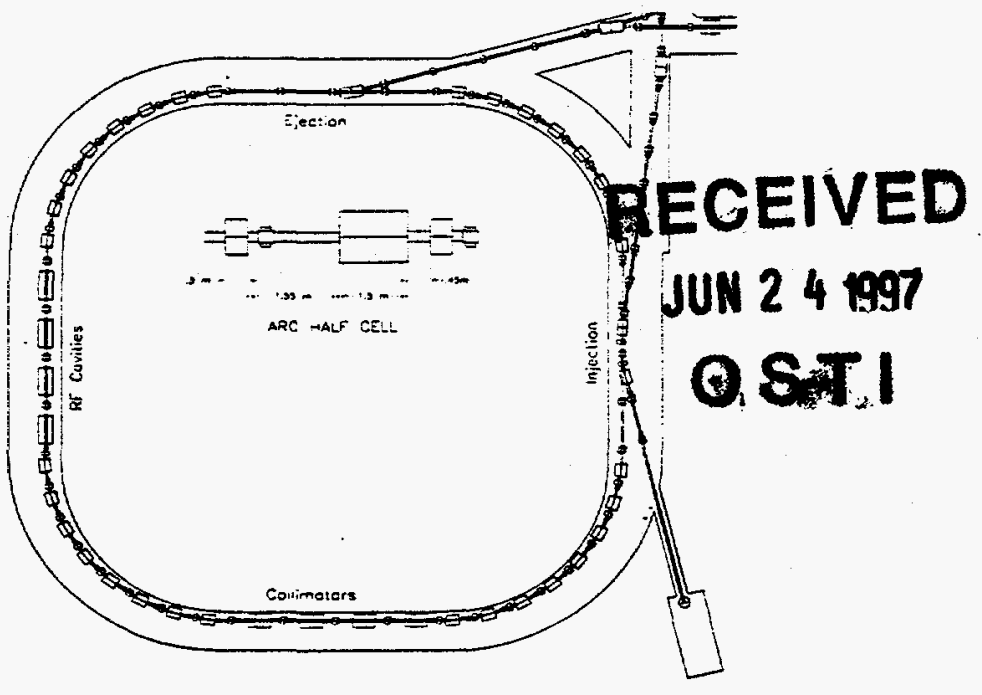

Figure 1: Layout of the accumulator ring.

riod, we have studied many possible technologies and design choices. Some of the considerations and rationals of choices are given here for comparison.

a. Accumulator Ring vs Rapid Cycling Synchrotron. The AR option is chosen for better injection efficiency, no eddy current effects and shorter beam-in-ring time to avoid coherent instabilities.

b. One vs Two Ring Tunnels. Separate tunnels for future upgrade is chosen for its simplicity in mechanical design, reliability in future operation, accessibility for maintenance, and low initial capital investment. Both the performance goal and specific design of the second ring can be decided at the time of upgrade.

c. FODO vs Triplet Lattice. A FODO lattice is chosen for its smoothness in betatron function variation around the ring. Such a property will minimize the possible envelope oscillation for beam with large space charge tune shift.

d. Normal vs lsochronous Lattice. Our choice is for a normal lattice, even if, at a first look, isochronous lattice may offer the advantage of constant longitudinal extend of the injected beam. However, it hurs in many other ways. For example, the higher order chromatic effects in lattice, reduction in dynamic aperture, and the reduction in Landau damping for transverse instabilities.

e. Single, Dual, Barrier Cavity RF Systems. The dual harmonic RF system is chosen for its advantage in 
higher bunching factor and established performances. The barrier cavity system holds promises of keeping the beam within the confine of the RF bucket and leaving the gap clean. However, it requires more RF stations and the beam dynamics related to beam loading and coherent instabilities is not well-understood.

\section{LATTICE, $H^{-}$INJECTION AND RF STACKING}

The accumulator ring of the National Spallation Neutron Source (NSNS) will have a four-fold symmetric lattice. The latitice will accommodate the long straight sections required for the injection system, the extraction system, the $R F$ cayities, and the beam scraping system. The straight sections will be dispersion free, which is desirable, especially for the RF cavities and the injection system. The lattace will provide ease of betatron tuning and flexibility of operation. Unlike lattices of lower symmetry, a lattice of four-fold symmetry will assure that there are no dangerous betatron structure resonances other than for the integer tune. Details of lattice design is given in ref. [4]. Lattice functions and other salient performance and design parameters of the accumulator ring are summarized in Table 1.

Table 1: NSNS Accumulator ring parameters

\begin{tabular}{|l|l|}
\hline Beam Average Power & $1.0 \mathrm{MW}$ \\
Kinetic Energy & $1.0 \mathrm{GeV}$ \\
Average Current & $1.0 \mathrm{~mA}$ \\
Repetition Rate & $60 \mathrm{~Hz}$ \\
Ion Source Peak Current & $35 \mathrm{~mA}$ \\
Linac Peak Current & $27.7 \mathrm{~mA}$ \\
Beam Duty Cycle & $6.18 \%$ \\
Linac Pulse Length & $1.03 \mathrm{msec}$ \\
Beam Loss (Controlled/Uncontrolled) & $<2 / 0.02 \%$ \\
Number of Turns Injected & 1225 \\
Revolution Period & $0.8413 \mu \mathrm{sec}$ \\
Revolution Frequency & $1.1886 \mathrm{MHz}$ \\
Circumference & $220.688 \mathrm{~m}$ \\
Space-Charge Tune-Shift & $<0.1$ \\
Bunching Factor (Dual RF Systems) & 0.405 \\
Number of Protons/Ring & $1.04 \times 10^{14}$ \\
Beam Emittance (Transverse, norm.) & $217 \pi \mathrm{mm}$-mr \\
Tunes $\nu_{x} / \nu_{y}$ & $5.82 / 5.80$ \\
$\beta_{\text {max }}$ (x/y) & $19.2 / 19.2 \mathrm{~m}$ \\
Dispersion $X_{p}$ (max/min) & $4.1 / 0.0 \mathrm{~m}$ \\
Transition Energy $\gamma_{t}$ & 4.93 \\
RF Voltage (1 ${ }^{s t}$ Harmonic) & $40 \mathrm{kV}$ \\
RF Voltage (2 ${ }^{\text {nd }}$ Harmonic) & $20 \mathrm{kV}$ \\
RF bucket & $17 \mathrm{eV}-\mathrm{sec}$ \\
Beam Emittance (Longitudinal) & $10 \mathrm{eV}-\mathrm{sec}$ \\
Beam Gap (injection) & $295 \mathrm{nsec}$ \\
Injected Pulse Length & $546 \mathrm{nsec}$ \\
Vacuum & $10^{-9} \mathrm{Tor}$ \\
\hline
\end{tabular}

The most demanding system in the design of the $1 \mathrm{MW}$ short pulse spallation neutron source is the $H^{-}$multi-rum injection into the storage ring. For the NSNS accumulator ring, a carbon foil of $400 \mu \mathrm{g} / \mathrm{cm}^{2}$ is assumed. The stripping efficiency for $1 \mathrm{GeV}$ incident $H^{-}$beam is about $99.8 \%$. The temperature rise for the $1 \mathrm{MW}$ design is estimated to be about $3200^{\circ} \mathrm{C}$. In addition, it has been found that [5]

a. Stripping losses in passage of the $\mathrm{H}^{-}$beam through the $B=3 \mathrm{kG}$ field in a DC bump dipole magnet upstream of the stripper foil are negligible.

b. A fraction $f\left(H^{\circ}\right)=8.19 \times 10^{-3}$ of the incident $H^{-}$ beam will emerge as $H^{\circ}$ from a $400 \mu \mathrm{g} / \mathrm{cm}^{2}$ carbon stripper foil and must be disposed of in an external dump.

c. Field ionization of the $H^{\circ}$ component in the $\mathrm{B}-2.41 \mathrm{kG}$ field of a quadrupole downstream of the foil will lead to negligible uncontrolled losses.

d. Fractional losses from nuclear non-elastic interactions in the foil as low as $1.26 \times 10^{-5}$ can be realized with rapidly (exponentially) collapsing injection bumps and "smoke-ring" injection scheme which result in very small multiple foil traversals of $\left\langle N_{t}\right\rangle=2.43$ traversals/injected proton.

e. Multipole Coulomb and nuclear elastic scattering fractional losses out of a ring acceptance of $A_{x, y}=330 \pi \mathrm{mm}$-mrad for the above injection conditions are $1.35 \times 10^{-5}$, well below our loss criterion of $<10^{-4}$. With the small area stripper foil (8mm HX $4 \mathrm{~mm} \mathrm{~V}$ ) used for the above estimates, $2.2 \%$ of the incident $H^{-}$beam misses the foil and will be defiected by a magnet to an external dump.

To accumulate all the particles needed and keep them in proper azimuthal distribution, a dual harmonic RF system is employed. The fundamental RF system will provide $40 \mathrm{kV}$ and the second harmonic RF system will provide $20 \mathrm{kV}$ to form a flattened $R F$ bucket for particle trapping with resulting bunching factor of about 0.4 . Such a RF system will reduce the incoherent tune shift by $25 \%$. The 4-dimensional multi-particle tracking program Accsim is needed to follow the 1200 turns of particles in the ring. The resultant beam distributions in real space and in RF phase space are shown in Fig. 2 and Fig. 3 respectively [6]. Much more work has to be done in this exercise to determine the optimal combination of RF waveform and injection strategy.

\section{BEAM LOSSES AND THEIR CONTROLS}

There are many possible beam loss mechanisms in addition to the foil stripping mentioned above. The important ones include:

a. Resonance crossing due to space charge tune shifts and magnetic imperfections. This will be minimized by controlling the tune shift to be less than 0.1 unit and provide all necessary multipole corrections up to order 3. 


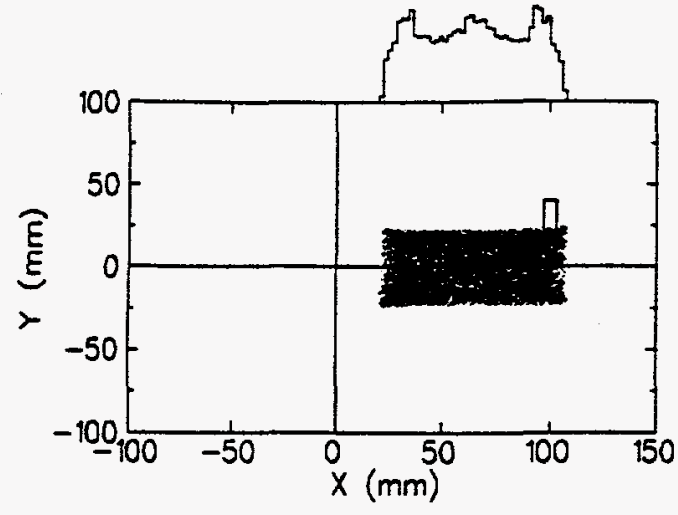

Figure 2: The resultant beam distributions in real space. Accsim snapshot at 1200 turns. Pseudo barrier RF.

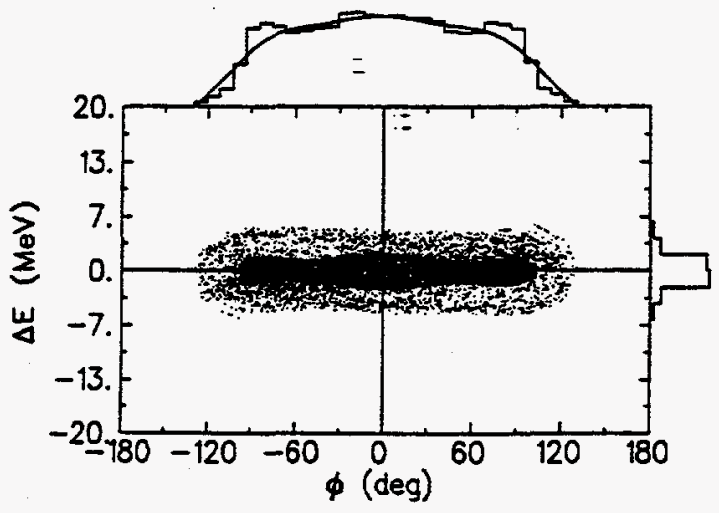

Figure 3: The resultant beam distributions in RF phase space. Accsim snapshot at 1200 turns. Pseudo barrier RF.

b. Coherent instabilities induced by impedance of the vacuum components. Careful studies have shown that all known instabilities will not occur with our design choices, except possible transverse instability. Further reduction of impedance will be attempted and a transverse damper will be provided to damp possible transverse instability [7].

c. $e-p$ instability can limit the achievable intensity if excessive $e^{-}$generation is allowed to occur. For the NSNS design, a vacuum pressure of less than $10^{-9}$ Torr and clear beam gap of 295 nsec should keep the neutralization coefficient below $10^{-3}$ which will keep the beam stable. TiN coating of the vacuum chamber has been considered to further reduce the secondary emission of the electrons [8].

d. Halo formation has been proposed as one of the possible beam loss mechanisms due to the particle-core resonance effect. Detailed studies will be carried out to better understand this phenomenon and its impact on the ring design and ultimate performance.

To contain those particles inadvertently migrating toward the wall, after all careful considerations and provisions, a collimator system is designed to catch the bulk of them before hitting the wall. Four collimators, $3.2 \mathrm{~m}$ each, enclosing a $4 \pi$ solid angle around the source point and stuffed with segmented material to capture all secondary particles generated by the incident protons will be provided to reduce the radiation effects by a factor of 100 . This way, most of uncontrolled losses will occur at the collimator, leaving ring components relatively intact for reliable operation [9].

\section{UPGRADE TO HIGHER POWER}

The design presented in this paper is for initial performance of $1 \mathrm{MW}$ average proton beam power. All accelerator issues, such as: space charge, tune shift, coherent instabilities, $e-p$ instabilities, ...etc. have been considered and designed for $2 \mathrm{MW}$ capability. For phase I upgrade to $2 \mathrm{MW}$ performance, the peak current for the linac will be increased for $28 \mathrm{~mA}$ to $56 \mathrm{~mA}$. No major changes in the ring will occur except modification in the kicker pulser and increase of shielding around high loss areas.

The most straightforward way to achieve $4 \mathrm{MW}$ is to build second identical ring and combine the beam power into single target station. In that case, the injection time into one ring will be reduced from $1 \mathrm{msec}$ to $0.5 \mathrm{msec}$. If the community of the users require more peak power, a bigger accumulator ring or synchrotron to higher beam energies can also be contemplated.

\section{ACKNOWLEDGMENTS}

The authors would like to thank the assistances and contributions to this work from many staff members from BNL and the NSNS collaboration Laboratories.

\section{REFERENCES}

[1] B.R. Appleton et al.: 'The NSNS Collaboration', Proc. EPAC'96, p.575, Sitges, Spain, 1996.

[2] D. Raparia et al:: 'The NSNS high energy beam transport line', in these proceedings.

[3] D. Raparia et al:: "The NSNS ring to target beam transport line', BNL/NSNS Tech. Note \#6, October, 1996.

[4] Y.Y. Lee, CJ. Gardner and A.U. Luccio: 'Accelerator ring lattice for the National Spallation Neutron Source", in these proceedings.

[5] L.N. Blumberg and Y.Y. Lee: ' $H$ - charge exchange injection into the $1 \mathrm{GeV}$ NSNS accumulator', BNLNSNS Tech. Note \#3, November, 1996.

[6] A.U. Luccio, J. Beebe-Wang and D. Maletic: 'Proton Injection and RF Capture in the National Spallation Neutron Source', in these proceedings.

[7] A.G. Ruggiero: 'Space charge and coherent effects in the NSNS storage ring", BNL/NSNS Tech. Note \#7, June, 1996.

[8] A.G. Ruggiero: ' $e-p$ instability in the NSNS accumulator ring', in these proceedings.

[9] H. Ludewig, S. Mughabghab and M. Todosow: 'NSNS ring system design study, collimation and shielding', BNLNSNS Tech. Note \#5, November, 1996. 


\section{DISCLAIMER}

This report was prepared as an account of work sponsored by an agency of the United States Government. Neither the United States Government nor any agency thereof, nor any of their employees, makes any warranty, express or implied, or assumes any legal liability or responsibility for the accuracy, completeness, or usefulness of any information, apparatus, product, or process disclosed, or represents that its use would not infringe privately owned rights. Reference herein to any specific commercial product, process, or service by trade name, trademark, manufacturer, or otherwise does not necessarily constitute or imply its endorsement, recommendation, or favoring by the United States Government or any agency thereof. The views and opinions of authors expressed herein do not necessarily state or reflect those of the United States Government or any agency thereof. 


\section{DISCLAMMER}

Portions of this document may be illegible in electronic image products. Images are produced from the best available original document. 